\title{
Resposta do feijão-caupi as lâminas de irrigação e as doses de fósforo no cerrado de Roraima ${ }^{1}$
}

\author{
Response of cowpea to water levels and phosphate fertilizer on the savanna of \\ Roraima
}

\author{
Gabriela Almeida Oliveira ${ }^{2}$, Wellington Farias Araújo ${ }^{3 *}$, Pablo Lima Souza Cruz ${ }^{4}$, Washington Luis Manduca \\ da Silva ${ }^{4}$ e Gilvan Barbosa Ferreira ${ }^{5}$
}

\begin{abstract}
Resumo - O objetivo do trabalho foi estudar o comportamento do feijão-caupi (Vigna ungüiculata (L.) Walp.) cv. BRS Novaera sob quatro lâminas de água $(273 ; 257 ; 241 \mathrm{e} 187 \mathrm{~mm})$ e doses de fósforo $\left(0 ; 70 ; 140 ; 210 \mathrm{~kg} \mathrm{ha}^{-1} \mathrm{de}_{2} \mathrm{O}_{5}\right.$, aplicados na forma de superfosfato triplo), em Boa Vista, Roraima. O delineamento experimental adotado foi o de blocos ao acaso, no esquema de parcelas subdivididas com quatro repetições. As parcelas foram constituídas pelas lâminas de água e as sub parcelas pelas doses de fósforo, resultando em 16 tratamentos. A irrigação foi realizada por um sistema convencional de aspersão, montado no campo segundo o sistema de "aspersão em linha". As massas seca da parte aérea e de 100 grãos foram influenciadas significativamente pela interação entre lâminas de água e doses de fósforo, enquanto o número de grãos por vagem e o comprimento da vagem foram influenciados somente pelas doses de fósforo. A dose de máxima efíciência econômica foi de $89,45 \mathrm{~kg}$ de $\mathrm{P}_{2} \mathrm{O}_{5}$, com produtividade de $1.306 \mathrm{~kg} \mathrm{ha}^{-1}$.
\end{abstract}

Palavras-chave - Vigna ungüiculata. Manejo da irrigação. Amazônia.

\begin{abstract}
This work was carried out to evaluate the effect of irrigation depth and phosphate fertilizer $\left(0 ; 70 ; 140 ; 210 \mathrm{~kg} \mathrm{ha}^{-1}\right.$ de $\mathrm{P}_{2} \mathrm{O}_{5}$ ) on yield and production components of cowpea (Vigna unguiculata L. Walp) cv. Novaera at the Savanna of Roraima, Brazil. The experimental design was arranged in a completely randomized block in split-plot and four replications. Irrigation depths were applied through a sprinkler line source system. The principal treatments constituted on the depths of irrigation and the secondary treatments by the phosphate fertilizer. Significant effects $(p<0.05)$ of the depth of irrigation and phosphate fertilizer interaction with aerial mass production and mass of 100 grains were observed. The number of grains per pods and size of pod were affected by the phosphate fertilizer only. The highest economical yield $\left(1,306 \mathrm{~kg} \mathrm{ha}^{-1}\right)$ was obtained by $89.45 \mathrm{~kg}$ of $\mathrm{P}_{2} \mathrm{O}_{5}$.
\end{abstract}

Key words - Vigna unguiculata. Irrigation management. Amazônia.

\footnotetext{
* Autor para correspondência

${ }^{1}$ Recebido para publicação em 14/06/2010; aprovado em 25/04/2011

Pesquisa financiada pelo PROAP/CAPES, parte de dissertação

${ }^{2}$ Programa de Pós-Graduação em Agronomia, CCA/UFRR, Boa Vista-RR, Brasil, gabiufrr@bol.com.br

${ }^{3}$ Departamento de Solos e Engenharia Agrícola, CCA/UFRR, Boa Vista-RR, Brasil, wellington@cca.ufrr.br

${ }^{4}$ Programa de Iniciação cientifica PIBIC/CNPq, CCA/UFRR, Boa Vista-RR, Brasil, pablo-lima-@hotmail.com, washingtonlms@hotmail.com

${ }^{5}$ Embrapa Roraima-Boa Vista-RR, Brasil, gilvan@cpafrr.embrapa.br
} 


\section{Introdução}

Nas Regiões Norte e Nordeste, o feijão-caupi constitui uma das principais alternativas sociais e econômicas de suprimento alimentar e geração de emprego, pelo alto valor nutritivo e baixo custo de produção. É amplamente cultivado pelos pequenos produtores, constituindo um dos principais componentes da dieta alimentar (FREIRE FILHO et al., 2005).

A predominância do cultivo do feijão-caupi na agricultura de subsistência e a falta de um banco de dados próprios, desvinculado do feijão comum, gera dúvidas quanto à precisão do total de área plantada e a produtividade média do feijão-caupi no âmbito nacional. Estima-se que $70 \%$ do feijão produzido no território brasileiro seja de feijão comum e $30 \%$ do feijão-caupi. Quanto à produtividade, a média foi de $777 \mathrm{~kg} \mathrm{ha}^{-1}$, considerando dados entre 2000 e 2007 (FILGUEIRAS et al., 2009). Como forma de elevar a produtividade da cultura, baixar os custos de produção e elevar a renda do produtor rural é fundamental a adoção de tecnologias, tais como: o manejo adequado da irrigação e da adubação.

Para um correto manejo de irrigação, deve-se levar em consideração a lâmina de irrigação adequada para um bom suprimento hídrico, evitando estresse à cultura, que possa afetar o crescimento das plantas, afetando a produção (BEZERRA et al., 2003).

Em relação à adubação, a aplicação de fósforo na cultura do feijoeiro promove aumento da produção de matéria seca da parte aérea, aumento do número de vagens e massa de grãos, influenciando a produtividade (YAMADA; ABDALLA, 2003). Trabalhos com adubação fosfatada na cultura do feijão comum tem apresentado respostas significativas (SILVA et al. 2002; VALDERRAMA et al., 2009) que, com o uso da irrigação, pode-se conseguir diferentes combinações de doses de $\mathrm{P}$ e lâminas de água para bons rendimentos (MIRANDA et al., 2000). No entanto, os estudos envolvendo tais combinações são limitados ao feijão comum.

Oconhecimentomais detalhadododesenvolvimento do feijão-caupi, em função das interações entre lâminas de água e níveis de adubação fosfatada, torna-se um importante fator para gerar tecnologia de baixo custo com aumento da produção. Neste trabalho, estudaramse as influências do manejo da irrigação e da adubação fosfatada na produtividade de grãos e seus componentes para a cultura do feijão-caupi.

\section{Material e métodos}

O experimento foi conduzido nos meses de fevereiro a abril de 2009, em área de primeiro ano de cultivo, em cerrado, pertencente à Universidade Federal de Roraima, no município de Boa Vista-RR, cujas coordenadas geográficas de referência são: $2^{\circ} 40^{\prime} 11^{\prime \prime} \mathrm{N}$ de latitude, 604'24" W de longitude e $90 \mathrm{~m}$ de altitude.

De acordo com Araújo et al. (2001), na região, a temperatura média do ar é de $27,4{ }^{\circ} \mathrm{C}$; a evaporação média anual é de 1.940,3 mm; a umidade relativa média é de $74 \%$ e a pluviosidade média anual é de $1.685,6 \mathrm{~mm}$; com uma estação chuvosa, de abril a setembro, e outra seca, de outubro a março. Durante a realização do experimento, foi registrado, por meio de estação automática, precipitação de $97 \mathrm{~mm}$, temperatura média $28,3{ }^{\circ} \mathrm{C}$, com mínima de $23,7^{\circ} \mathrm{C}$ e máxima de $34^{\circ} \mathrm{C}$. A umidade relativa apresentou média de $69 \%$.

O solo da área é classificado como Latossolo amarelo Distrófico, textura média, cujas características físicas e químicas encontram-se na Tabela 1.

Tabela 1 - Características físicas e químicas do solo na camada de $0-20 \mathrm{~cm}$ de profundidade

\begin{tabular}{cc}
\hline Determinações & Valores \\
\hline $\mathrm{pH} \mathrm{em} \mathrm{H}_{2} 0(1: 2,5)$ & 4,21 \\
$\mathrm{Ca}^{2+}\left(\mathrm{cmol}_{\mathrm{c}} \mathrm{dm}^{-3}\right)$ & 0,38 \\
$\mathrm{Mg}^{2+}\left(\mathrm{cmol}_{\mathrm{c}} \mathrm{dm}^{-3}\right)$ & 0,10 \\
$\mathrm{Al}^{3+}\left(\mathrm{cmol}_{\mathrm{c}} \mathrm{dm}^{-3}\right)$ & 2,40 \\
$\mathrm{~K}^{+}\left(\mathrm{cmol}_{\mathrm{c}} \mathrm{dm}^{-3}\right)$ & 0,01 \\
$\mathrm{P}\left(\mathrm{mg} \mathrm{dm}^{-3}\right)$ & 3,89 \\
Areia grossa $(\%)^{\text {Areia fina }(\%)}$ & 43,60 \\
Silte $(\%)$ & 21,30 \\
Argila $(\%)$ & 13,10 \\
\hline
\end{tabular}

Um mês antes da semeadura foram aplicados, a lanço, $2.000 \mathrm{~kg} \mathrm{ha}^{-1}$ de calcário dolomítico, PRNT 100\%. A semeadura foi realizada em 27 de fevereiro de 2009 e, três dias antes, houve a adubação de base, a lanço, onde foram utilizados $40 \mathrm{~kg} \mathrm{ha}^{-1}$ de $\mathrm{K}_{2} \mathrm{O}$, na forma de cloreto de potássio e $50 \mathrm{~kg} \mathrm{ha}^{-1}$ de FTE-BR 12.

O preparo do solo constou de uma roçagem, deixando-se o material vegetal retirado sobre o solo. $\mathrm{O}$ plantio foi realizado com auxílio de uma matraca, num espaçamento de $0,5 \mathrm{~m}$ entre fileiras, com 8 sementes por metro linear, procurando-se obter uma população de 160.000 plantas ha-1 . Foi utilizada a cultivar BRS Novaera, de crescimento indeterminado e porte ereto, 
recomendada para a região (VILARINHO et al, 2006). As sementes foram inoculadas com Bradyrhizobium elkanii, na proporção de $100 \mathrm{~g}$ de inoculante, misturado com $30 \mathrm{~mL}$ de água, para $50 \mathrm{~kg}$ de sementes. Foram realizada 3 colheitas, de forma manual, a partir de 30 de abril de 2009.

O delineamento experimental foi o de blocos ao acaso, no esquema de parcelas subdivididas, com quatro repetições. As parcelas, com área de $54 \mathrm{~m}^{2}$ (3 m x $\left.18 \mathrm{~m}\right)$, foram constituídas pelas lâminas de água e as sub parcelas,

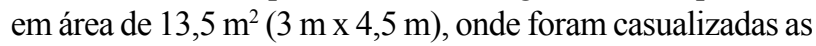
doses de fósforo, cuja área útil foi de $7 \mathrm{~m}^{2}$ (2 $\mathrm{m}$ x 3,5 m). Os tratamentos constaram de quatro lâminas de água $(273 ; 257$; 241 e $187 \mathrm{~mm}$ ), combinadas com quatro doses de fósforo (0; 70; 140 e $210 \mathrm{~kg} \mathrm{ha}^{-1}$ de $\mathrm{P}_{2} \mathrm{O}_{5}$ ), na forma de superfosfato triplo, resultando em 16 tratamentos (FIG. 1).

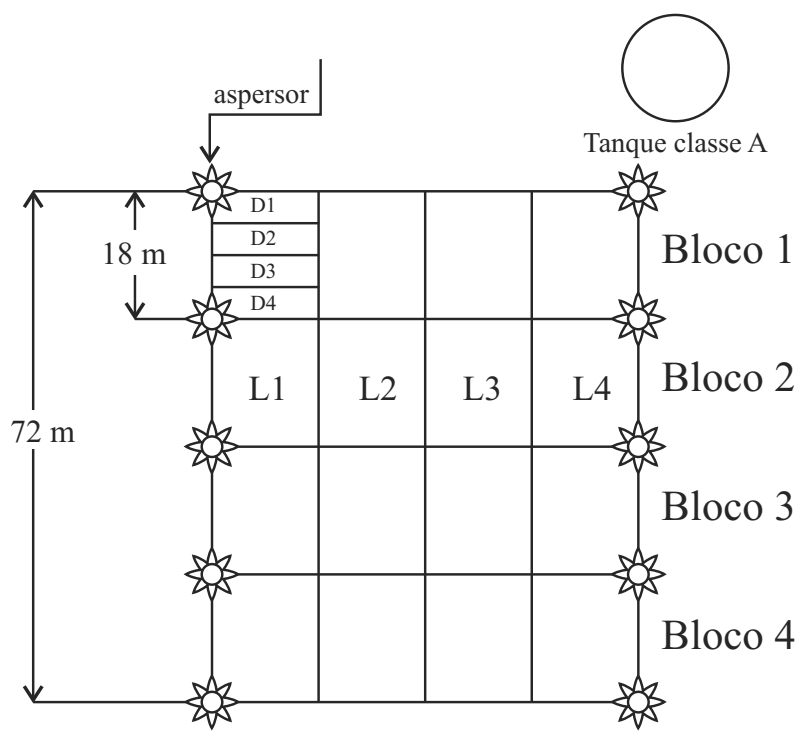

Figura 1 - Croqui da distribuição das unidades experimentais no campo

A irrigação foi realizada por um sistema convencional de aspersão, montado no campo segundo o sistema de "aspersão em linha" (HANKS et al., 1976). As irrigações ocorreram a cada dois dias, repondo-se a lâmina de água correspondente a evaporada medida pelo tanque Classe A, instalado junto à área experimental. A irrigação sempre ocorria nas horas de menor velocidade do vento.

Durante o estabelecimento da cultura, foram instaladas três linhas de aspersores, de modo a promover uma irrigação uniforme em toda a área experimental. $\mathrm{O}$ espaçamento era de $12 \mathrm{~m}$ entre aspersores e $8 \mathrm{~m}$ entre linha de aspersores.
Após 30 dias do início do experimento, a irrigação ocorreu somente em uma única linha com o uso de aspersores convencionais do tipo NAAN 5022, funcionando a uma pressão de serviço de $190 \mathrm{kPa}$, resultando numa intensidade de aplicação de $10,8 \mathrm{~mm} \mathrm{~h}^{-1}$. A medição das lâminas de água aplicadas por irrigação, em cada sub parcela experimental, foi feita mediante coletores, com área de captação de $22,06 \mathrm{~cm}^{2}$ e previamente distribuídos em cada bloco experimental, transversal à linha de aspersores (três por sub parcela), sendo a lâmina definida pela média da água coletada nesses pluviômetros. Posteriormente, logo após a irrigação, o volume coletado era convertido em mm, sendo a lâmina definida pela média da água coletadas nesses pluviômetros.

Esses dados serviram para estimar a lâmina precipitada em cada tratamento e calcular o coeficiente de uniformidade de distribuição de água, utilizando-se o coeficiente de Christiansen (1942), conforme a seguinte equação:

$$
\begin{aligned}
& \operatorname{CUC} 100\left(1-\frac{\sum_{\mathrm{i}=1}^{\mathrm{n}}[\mathrm{Ai}-\overline{\mathrm{A}}]}{\mathrm{n} \cdot \mathrm{A}}\right) \\
& \text { onde, }
\end{aligned}
$$

CUC - coeficiente de uniformidade de Christiansen, em porcentagem $(\%)$;

n - número de coletores;

$\mathrm{A}_{\mathrm{i}}$ - precipitação no coletor de ordem i, mm;

$\overline{\mathrm{A}}$ - média aritmética das precipitações, $\mathrm{mm}$.

O CUC resultou em $71 \%$, para uma média de velocidade de vento observada, durante os testes, de 1,8 $\mathrm{ms}^{-1}$. Segundo Merrian e Keller (1978), para culturas de alto rendimento econômico, com sistema radicular raso, a irrigação por aspersão deve apresentar alta uniformidade de distribuição. O CUC deve ser acima de $88 \%$. Para cultivos com sistema radicular médio, o CUC pode variar entre 80 e $88 \%$. Em culturas com sistema radicular profundo, o CUC pode variar entre 70 e $80 \%$. Devido a esses resultados, o horário de irrigação foi alterado para o fim da tarde/início da noite, quando há praticamente ausência de vento, propiciando maior uniformidade de distribuição de água e elevação do CUC.

Foram analisados as seguintes variáveis: massa seca da parte aérea (MSPA), comprimento de vagem por planta $(\mathrm{CV})$, número de grãos por vagem $(\mathrm{NG})$, massa de 100 grãos (MCG) e produtividade de grãos (PG). Também foi estimada a dose de fósforo correspondente a máxima eficiência econômica (DMEE), onde se igualou a derivada da curva de resposta da cultura à adubação fosfatada com a razão entre o preço do insumo (adubo fosfatado) e o preço comercial do produto (feijão-caupi) e calculou-se 
a dosagem do adubo que satisfaz essa igualdade. Para o cálculo, considerou-se um valor médio comercializado na feira local, durante o período experimental, de $\mathrm{R} \$ 1,50$ por quilo de feijão-caupi e o valor do adubo de $\mathrm{R} \$ 3,6$ por $\mathrm{kg}$ de $\mathrm{P}_{2} \mathrm{O}_{5}$.

Os resultados obtidos foram submetidos à análise de variância pelo teste $\mathrm{F}$, a 5\% de significância. Realizando-se a análise de regressão das lâminas de água e das doses de fósforo.

\section{Resultados e discussão}

Durante o ciclo da cultura, os valores das lâminas de irrigação, aplicadas nas parcelas, apresentaram um gradiente de variação decrescente a partir da linha central de aspersores, característica inerente ao sistema de aspersão em linha proposto por Hanks et al. (1976).

As lâminas totais de irrigação apresentaram valores abaixo dos encontrados por Andrade Júnior et al. (2002), que, em seus estudos de avaliação dos níveis de irrigação na cultura do feijão-caupi no estado do Piauí, obtiveram lâminas de água de 449,1 a 194,4 mm.

A interação entre os fatores lâminas de irrigação e doses de fósforo $(\mathrm{P})$ foi significativa apenas nas variáveis massa seca da parte aérea (MSPA) e massa de 100 grãos (MCG) (TAB. 2). Para os demais fatores em estudo, estudou-se o efeito isolado de cada fator. Verificou-se que os demais fatores em estudo ajustaram-se à regressão para o fator dose de fósforo, sendo que somente as variáveis massa seca da vagem e produtividade de grãos ajustaram-se a regressão para lâmina de irrigação (TAB. 2). A resposta da cultura ao fósforo, já era esperada, em função do baixo teor do elemento no solo e a baixa resposta das variáveis estudadas às lâminas de irrigação pode ser atribuída à baixa amplitude entre os tratamentos $(31,6 \%)$.
As plantas apresentaram MSPA que variaram de $6,26 \mathrm{~g}\left(0 \mathrm{~kg} \mathrm{ha}^{-1} \mathrm{de}_{2} \mathrm{O}_{5} \operatorname{com} 257 \mathrm{~mm}\right)$ a 47,06 g (210 $\mathrm{kg} \mathrm{ha}^{-1}$ de $\mathrm{P}_{2} \mathrm{O}_{5}$ com $273 \mathrm{~mm}$ ), estando de acordo com os resultados encontrados por Leite e Virgens Filho (2004), obtendo MSPA de até 30,27 g e Mendes et al. (2007), com média de 31,42 g de MSPA, por planta, em cultura de feijão-caupi. Também Matteucci e Carvalho (1988) encontraram valores de 12,1 a $36,6 \mathrm{~g}$ de massa seca, estudando quatro doses de $\mathrm{P}_{2} \mathrm{O}_{5}\left(0,40,80\right.$ e $\left.160 \mathrm{~kg} \mathrm{ha}^{-1}\right)$, em diferentes densidades de plantio, sendo que valores menores foram encontrados por Fonseca (2008), Linhares (2007) e maiores (54,32 g) foram encontrados por Lacerda et al. (2009), utilizando uma lâmina de 326,3 mm. Tais variações podem ser atribuídas às diferenças inerentes as cultivares usadas nas diferentes pesquisas e as condições edafoclimáticas de cada local.

Para MSPA do feijão-caupi, as doses 70 e $140 \mathrm{~kg} \mathrm{ha}^{-1}$ de $\mathrm{P}_{2} \mathrm{O}_{5}$ apresentaram efeitos lineares (FIG. 2), sendo que os maiores valores foram encontrados na maior lâmina de água $(273 \mathrm{~mm})$. A equação quadrática apresentou o melhor ajuste para MSPA referente a essa lâmina, com $210 \mathrm{~kg} \mathrm{ha}^{-1}$ de $\mathrm{P}_{2} \mathrm{O}_{5}$, com produção máxima de $47,05 \mathrm{~g}$ na maior lâmina de água $(273 \mathrm{~mm})$. Os menores valores observados para esta variável ocorreram com a combinação entre qualquer lâmina com a dose $0 \mathrm{~kg} \mathrm{ha}^{-1} \mathrm{de}$ $\mathrm{P}_{2} \mathrm{O}_{5}$, devido, possivelmente, aos baixos teores de fósforo observados no solo do experimento. A exigência de um maior nível de $\mathrm{P}$ para alcançar maior MSPA no solo em boas condições hídricas, significa que a absorção do elemento pelas plantas foi prejudicada pelo déficit hídrico. Isto poderia ter ocorrido pela diminuição da disponibilidade do P no solo e/ou pela maior dificuldade da absorção em si no solo com déficit hídrico. A primeira hipótese é corroborada, em princípio, pois os maiores teores de água aumentam a disponibilidade do $\mathrm{P}$, tanto pela maior solubilidade do elemento, quanto pela maior difusão do íon no solo nas maiores lâminas de irrigação. No entanto, Dutra et al. (1995), utilizando

Tabela 2 - Resumo da análise de variância da massa seca da parte aérea (MSPA), massa seca da vagem (MSV), massa de 100 grãos (MCG), número de grãos por vagem (NG), comprimento da vagem (CV) e produtividade de grãos $(\mathrm{PG})$

\begin{tabular}{cccccccc}
\hline \multirow{2}{*}{ FV } & GL & \multicolumn{5}{c}{ Quadrado Médio } \\
\cline { 3 - 7 } & & MSPA & MSV & MCG & NG & CV & PG \\
\hline BLOCO & 3 & $105,95^{\text {ns }}$ & 56,02 & $1,692372^{\text {ns }}$ & $1,4^{\text {ns }}$ & $0,62^{\text {ns }}$ & $1314078,1^{\text {ns }}$ \\
Lâmina (L) & 3 & $1351,11^{* *}$ & $429,90^{* *}$ & $15,721672^{*}$ & $2,49^{\text {ns }}$ & $1,57^{\text {ns }}$ & $2470573,5^{*}$ \\
erro a & 9 & & & & & & \\
Fósforo (P) & 3 & $1125,79^{* *}$ & $270,13^{* *}$ & $4,535514^{\text {ns }}$ & $8,33^{* *}$ & $3,92^{* *}$ & $1677141,0^{*}$ \\
L*P & 9 & $202,94^{*}$ & $58,77^{\text {ns }}$ & $7,509718^{* *}$ & $0,86^{\text {ns }}$ & $0,56^{\text {ns }}$ & $361292,9^{\text {ns }}$ \\
erro b & 36 & & & & & \\
\hline
\end{tabular}

$\mathrm{ns}, *$ ** - Não significativo, significativo a $5 \%$ e significativo a $1 \%$ pelo teste $\mathrm{F}$, respectivamente 


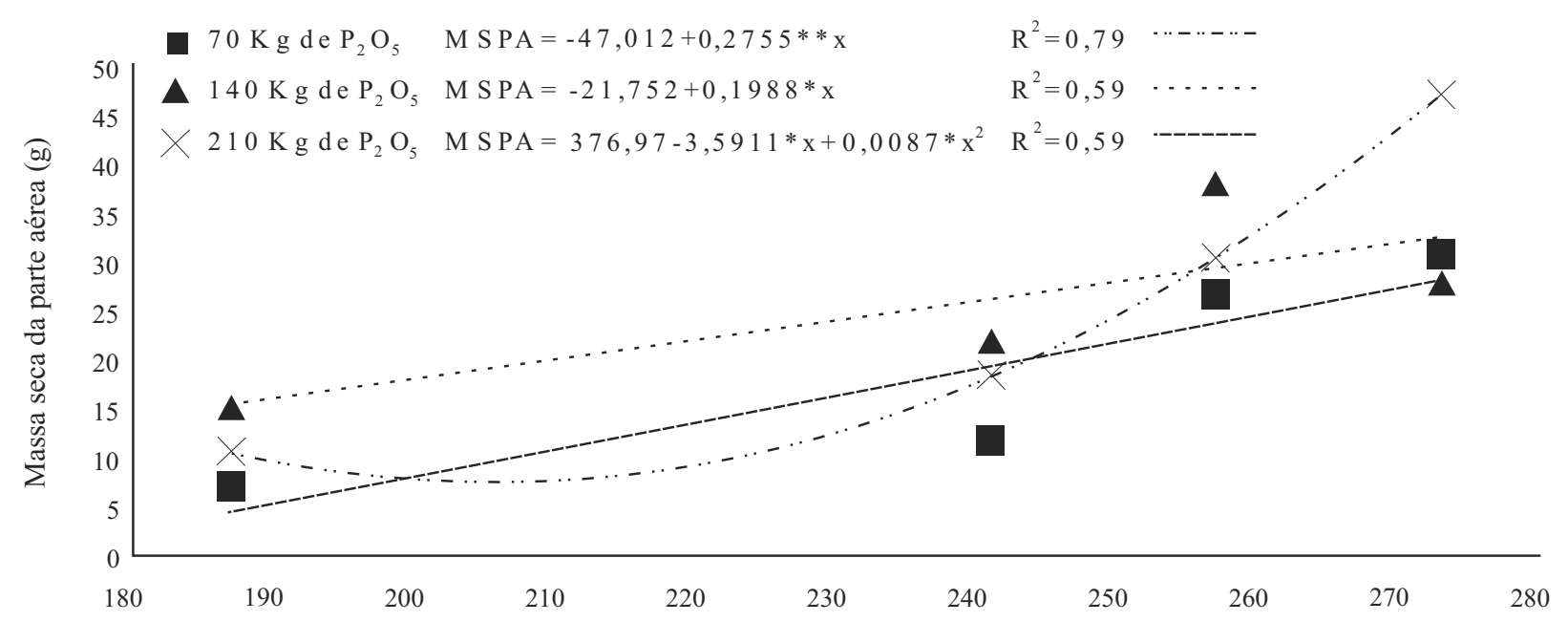

Lâmina (mm)

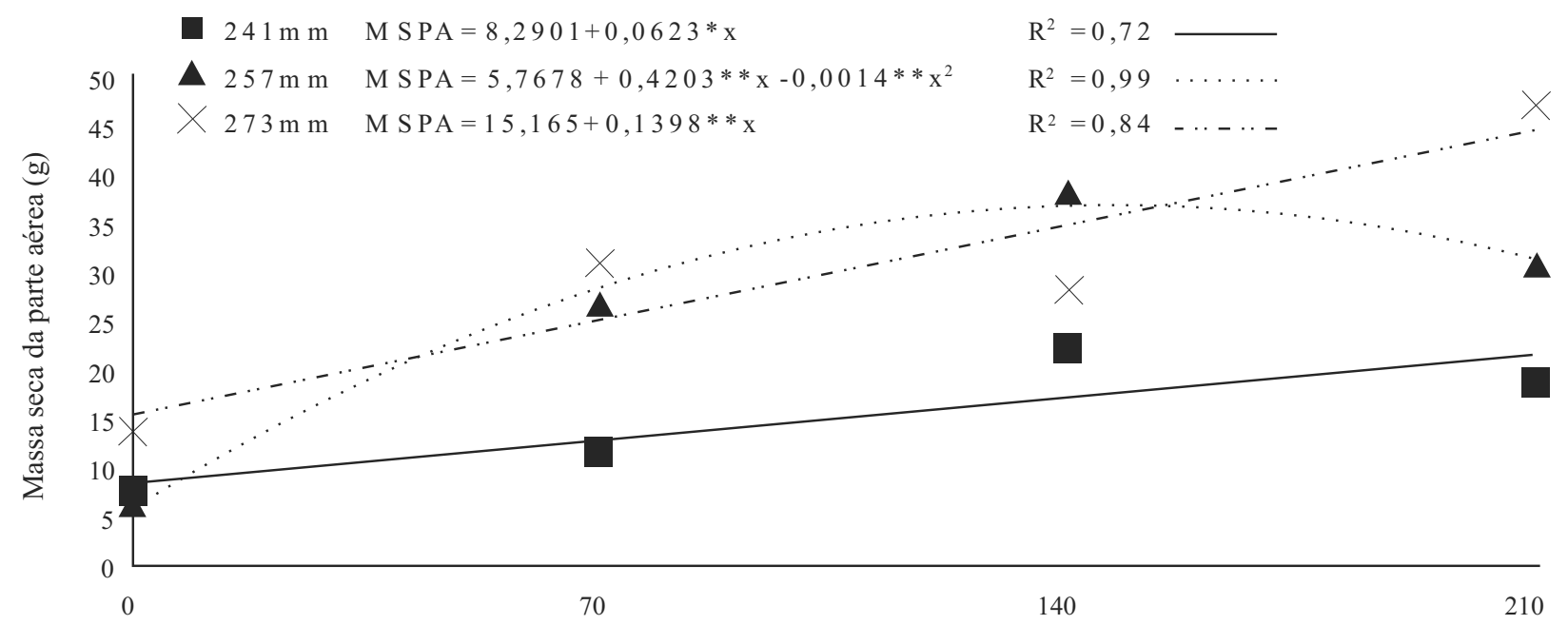

Dose de $\mathrm{P}_{2} \mathrm{O}_{5}\left(\mathrm{~kg} \mathrm{ha}^{-1}\right)$

*, ** - Significativo a 5 e $1 \%$ pelo teste de regressão

Figura 2 - Efeito das doses de fósforo (70, 140 e $210 \mathrm{~kg} \mathrm{ha}^{-1}$ de $\mathrm{P}_{2} \mathrm{O}_{5}$ ) aplicadas sob diferentes lâminas de irrigação na massa seca da parte aérea do feijão-caupi cv. Novaera (A). Efeito das lâminas de água (241, 257 e $273 \mathrm{~mm}$ ) aplicadas sob diferentes doses de fósforo na massa seca da parte aérea do feijão-caupi cv. Novaera (B), no cerrado de Roraima, 2009

feijão comum, não encontraram interação significativa entre doses de $\mathrm{P}$ e níveis de umidade no solo para MSPA.

Resultados com feijoeiro comum mostraram que a MSPA é uma das características da planta mais importantes para o aumento da produção, parâmetro que explicam $87 \%$ da variabilidade da produção de grãos (YAMADA; ABDALLA, 2003).

As limitações da disponibilidade de $\mathrm{P}$, no início do ciclo vegetativo, resultam em restrições no desenvolvimento, das quais a planta não se recupera posteriormente, mesmo aumentando o suprimento de $\mathrm{P}$ a níveis adequados. $\mathrm{O}$ suprimento de $\mathrm{P}$ é essencial desde os estádios iniciais de crescimento da planta (GRANT et al., 2001).

A matéria seca da vagem (MSV) apresentou efeito linear tanto para o fator dose como para o fator lâmina de irrigação (FIG. 3). A menor lâmina de irrigação aplicada reduziu a $\mathrm{MSV}$, independente das doses de fósforo, em 

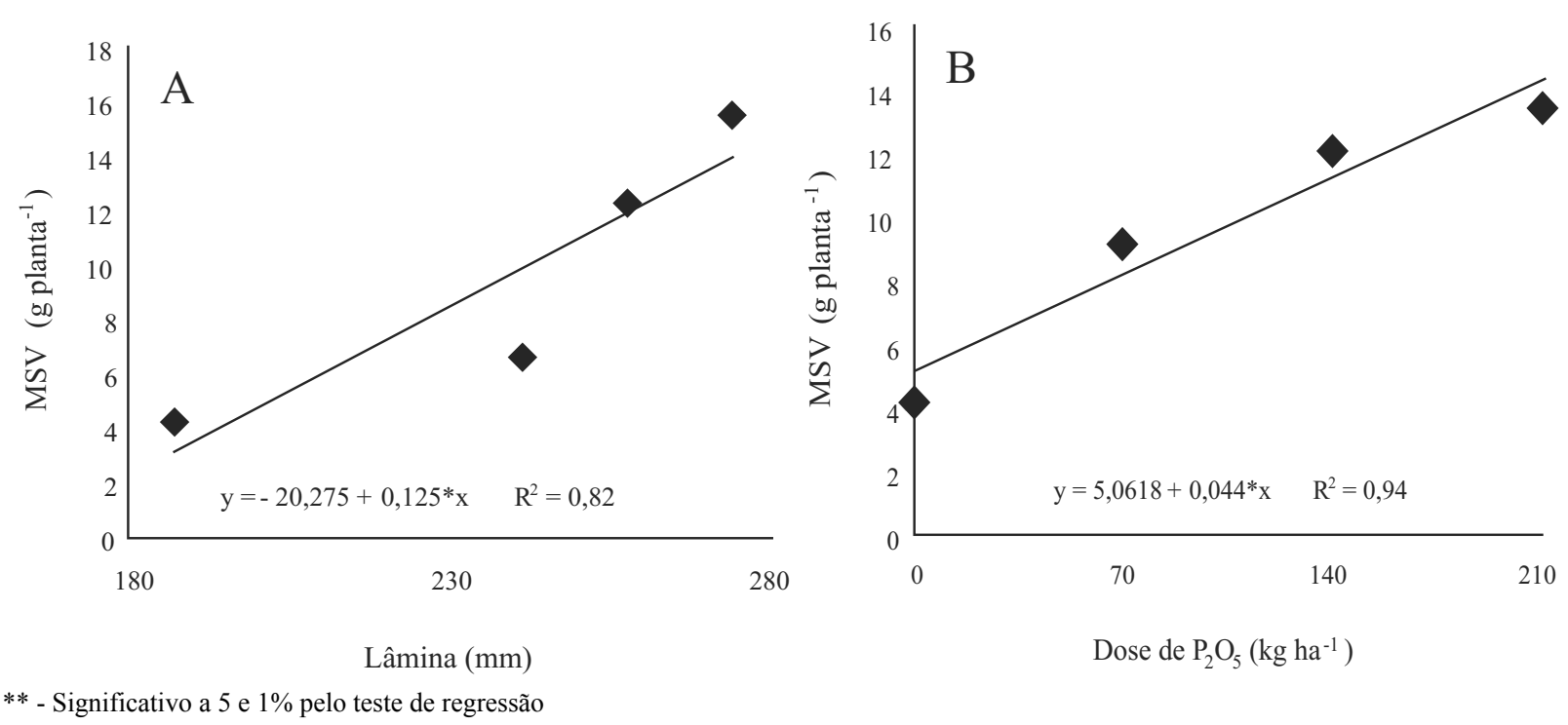

Figura 3 - Massa seca da vagem (MSV) de feijão-caupi em função de lâminas de água (A) e doses de fósforo (B), no cerrado de Roraima, 2009

$27,16 \%$, em relação ao tratamento com a maior lâmina de água. Costa et al. (1997); Leite e Virgens Filho (2004) encontraram uma redução de $56 \%$ e $61,3 \%$, respectivamente, quando o estresse hídrico foi imposto na fase reprodutiva. Já menores doses de adubo fosfatado reduziram a massa seca da vagem. Esse dado é corroborado por Grant et al. (2001), que relatam ser preciso garantir um suprimento contínuo de $\mathrm{P}$ até a fase de maturação, para permitir o funcionamento do mecanismo de translocação de carboidrato, para que não haja redução na produção de grãos.

A massa de 100 grãos apresentou média variando de 21,04 a $23,87 \mathrm{~g}$, exceto para o tratamento com a menor lâmina de água e a dose $0 \mathrm{~kg} h a^{-1}$ de $\mathrm{P}_{2} \mathrm{O}_{5}$ (TAB. 3). Em geral, os valores foram superiores ao descrito por Vilarinho et al. (2006), em estudo com o feijão-caupi BRS Novaera, no cerrado de Roraima, que obtiveram $20 \mathrm{~g}$ de MCG. Oliveira et al. (2003) relatam que a massa de 100 grãos é a segunda variável mais influente na seleção para produtividade em grãos de feijão-caupi. A MCG apresentou efeito significativo para interação das variáveis independentes (lâminas de irrigação e doses de fósforo), obtendo-se efeito significativo somente nas diferentes lâminas dentro da dose $0 \mathrm{~kg} \mathrm{ha}^{-1} \mathrm{de}$ $\mathrm{P}_{2} \mathrm{O}_{5}$ e diferentes doses dentro da lâmina de $187 \mathrm{~mm}$, com efeito linear e quadrático, respectivamente, com significância de 1\% (FIG. 4). A resposta significativa para o fator lâmina da água, na cultura do feijão-caupi, difere de outros trabalhos encontrados na literatura (QUEIROZ P. FILHO et al., 1986; TÁVORA; LOPES 1990; FERREIRA et al., 1991; BEZERRA et al., 2003; MENDES et al., 2007).
Quanto a resposta da interação, somente na dose 0 de P e 187 mm de irrigação corroboram com Yamada; Abdalla (2003), no qual relatam que, sob condições limitantes de P, as plantas normalmente apresentam menor desenvolvimento de raízes e, como resultado, ocorre exploração insuficiente do solo, resultando em acesso restrito e baixa eficiência de uso, tanto de água quanto de nutrientes.

Valderrama et al. (2009) não verificaram resposta de MCG para diferentes dose de $\mathrm{P}\left(0\right.$ a $150 \mathrm{~kg} \mathrm{ha}^{-1} \mathrm{de}$ $\mathrm{P}_{2} \mathrm{O}_{5}$ ) aplicadas no feijão comum. Porém, Coleta et al. (2008) encontraram que a MCG do feijoeiro apresentou menores valores no tratamento testemunha com zero de $\mathrm{P}$ e, para as demais doses de $\mathrm{P}$, não se houve diferenças estatísticas.

O número de grãos por vagem e o comprimento de vagem por planta apresentaram efeito significativo apenas em doses de fósforo (TAB. 2). Ambas variáveis apresentaram efeito linear (TAB. 4). No presente trabalho, valores menores de $\mathrm{NG}$ foram encontrados nas menores doses de P (TAB. 3), confirmando a importância do fósforo nos componentes de produção. Vilarinho et al. (2005), estudando o desempenho produtivo de linhagens de feijão-caupi em Roraima, encontraram valores de 10,4 a 22,6 $\mathrm{cm}$ para comprimento médio das vagens e 4 a 18 grãos por vagem, sendo que para a cultivar Novaera, Vilarinho et al. (2006) descrevem $15 \mathrm{~cm}$ de comprimento e 10 grãos por vagem.

Os valores de comprimento de vagem foram semelhantes aos encontrados por Queiroz P. Filho et 
Tabela 3 - Médias estimadas das variáveis agronômicas de feijão-caupi cv. Novaera submetidas a quatro lâminas de irrigação e quatro doses de adubação fosfatada

\begin{tabular}{|c|c|c|c|c|c|}
\hline \multirow{2}{*}{ Lâmina (mm) } & \multicolumn{4}{|c|}{ Dose de $\mathrm{P}_{2} \mathrm{O}_{5}\left(\mathrm{~kg} \mathrm{ha}^{-1}\right)$} & \multirow{2}{*}{ Média } \\
\hline & 0 & 70 & 140 & 210 & \\
\hline & \multicolumn{4}{|c|}{ Massa seca da parte aérea por planta $(\mathrm{g})$} & \\
\hline 187 & 2,56 & 2,39 & 7,32 & 4,63 & 4,22 \\
\hline 241 & 2,70 & 3,37 & 10,81 & 9,55 & 6,61 \\
\hline 257 & 3,17 & 13,59 & 17,56 & 15,03 & 12,34 \\
\hline 273 & 8,09 & 17,15 & 12,48 & 24,44 & 15,54 \\
\hline \multirow[t]{2}{*}{ Média } & 4,13 & 9,12 & 12,04 & 13,41 & \\
\hline & \multicolumn{4}{|c|}{ Massa seca das vagens $(\mathrm{g})$} & \\
\hline 187 & 6,98 & 6,91 & 15,33 & 10,64 & 9,96 \\
\hline 241 & 7,41 & 11,46 & 22,04 & 18,42 & 14,83 \\
\hline 257 & 6,26 & 26,72 & 38,07 & 30,52 & 25,39 \\
\hline 273 & 13,52 & 30,79 & 28,00 & 47,06 & 29,84 \\
\hline \multirow[t]{2}{*}{ Média } & 8,54 & 18,97 & 25,86 & 26,66 & \\
\hline & \multicolumn{4}{|c|}{ Massa de 100 grãos (g) } & \\
\hline 187 & 17,46 & 22,59 & 22,75 & 21,04 & 20,96 \\
\hline 241 & 23,00 & 23,34 & 22,70 & 22,98 & 23,01 \\
\hline 257 & 22,86 & 23,23 & 22,92 & 22,49 & 22,87 \\
\hline 273 & 23,87 & 23,10 & 22,07 & 22,72 & 22,94 \\
\hline \multirow[t]{2}{*}{ Média } & 21,80 & 23,07 & 22,61 & 22,31 & \\
\hline & \multicolumn{4}{|c|}{ Comprimento de vagem $(\mathrm{cm})$} & \\
\hline 187 & 12,58 & 13,82 & 13,90 & 14,01 & 13,58 \\
\hline 241 & 14,26 & 14,23 & 14,12 & 14,48 & 14,27 \\
\hline 257 & 13,02 & 13,67 & 14,34 & 14,69 & 13,93 \\
\hline 273 & 13,52 & 14,23 & 14,03 & 14,99 & 14,19 \\
\hline \multirow[t]{2}{*}{ Média } & 13,35 & 13,99 & 14,10 & 14,54 & \\
\hline & \multicolumn{4}{|c|}{ Número de grãos } & \\
\hline 187 & 5,73 & 7,00 & 6,87 & 7,53 & 6,78 \\
\hline 241 & 7,20 & 7,53 & 7,70 & 8,10 & 7,63 \\
\hline 257 & 6,27 & 7,35 & 8,50 & 8,00 & 7,53 \\
\hline 273 & 6,55 & 7,20 & 7,40 & 9,00 & 7,54 \\
\hline \multirow[t]{2}{*}{ Média } & 6,44 & 7,27 & 7,62 & 8,16 & \\
\hline & \multicolumn{4}{|c|}{ Produtividade $\left(\mathrm{kg} \mathrm{ha}^{-1}\right)$} & \\
\hline 187 & 44,54 & 666,42 & 1011,32 & 737,61 & 614,97 \\
\hline 241 & 537,41 & 1306,21 & 849,09 & 1011,93 & 926,16 \\
\hline 257 & 920,74 & 2229,13 & 1380,76 & 1103,93 & 1408,64 \\
\hline 273 & 1279,25 & 1751,36 & 1091,75 & 1559,68 & 1420,51 \\
\hline Média & 695,49 & 1488,28 & 1083,23 & 1103,29 & \\
\hline
\end{tabular}

al. (1986) e Santos et al. (2009). Não foi observado efeito significativo do comprimento de vagem para as diferentes lâminas de irrigação. Resultados similares aos encontrados na literatura (ANDRADE JÚNIOR, 2002; BEZERRA et al., 2003; MENDES et al., 2007). No entanto, Nascimento et al. (2004) obtiveram 

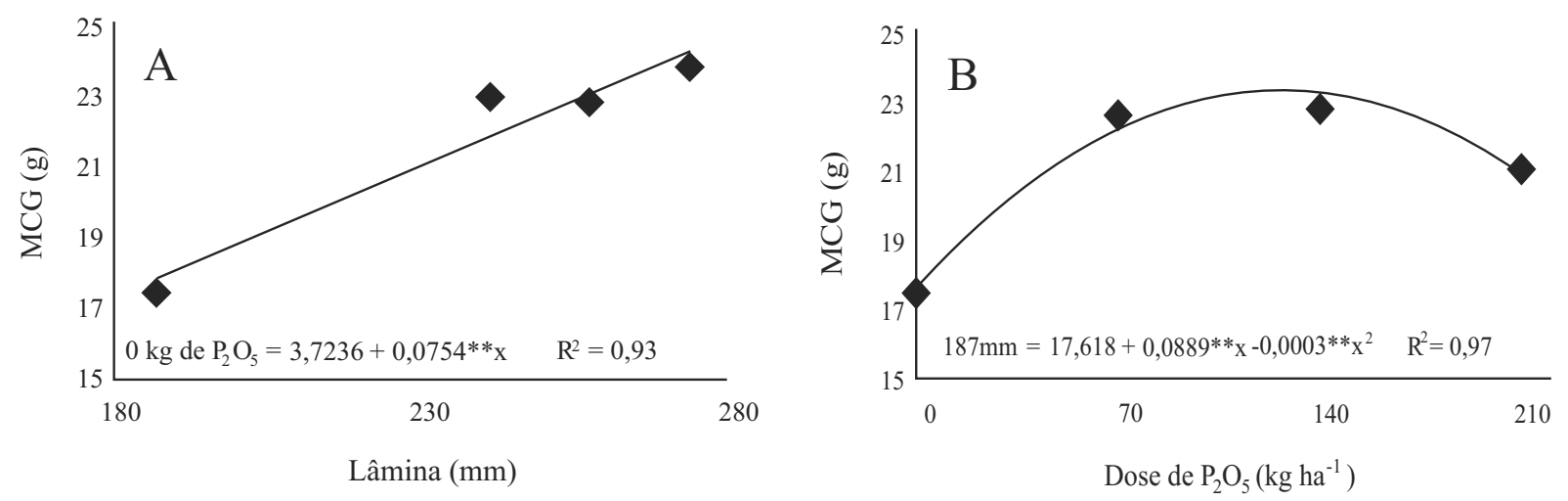

*, ** - Significativo a 5 e $1 \%$ pelo teste de regressão

Figura 4 - Massa de 100 grãos (g) de feijão-caupi em função de lâminas de água (A) e doses de fósforo (B), no cerrado de Roraima, 2009

diferenças significativas de níveis de água disponível no solo para o comprimento de vagem. Oliveira et al. (2003) relatam que o número médio de grãos por vagem é uma variável de pouca importância direta na seleção para o aumento da produtividade.

Tabela 4 - Equações de regressão para número de grãos por vagem (NG) e comprimento de vagem por planta (CV) de feijãocaupi em função das doses de fósforo

\begin{tabular}{cc}
\hline Equações de regressão & $\mathrm{R}^{2}$ \\
\hline $\mathrm{NG}=6,5446+0,0079^{* *} \mathrm{x}$ & 0,97 \\
$\mathrm{CV}=13,436+0,0053^{* *} \mathrm{x}$ & 0,94 \\
\hline
\end{tabular}

*, ** - Significativo a 5 e $1 \%$ pelo teste de regressão

Foi possível obter equações lineares entre número de grãos por vagem e lâmina de água e comprimento de vagem por planta e lâmina de água (TAB. 4). Estes resultados são similares aos obtidos por Costa et al. (1997) e Leite et al. (2000), que encontraram reduções no número de grãos por vagem, com a aplicação do estresse hídrico na fase reprodutiva em feijão-caupi. Entretanto, são divergentes dos obtidos por Queiroz P. Filho et al. (1986), que não observaram diferenças significativas entre os tratamentos com diferentes lâminas de água para a variável número de grãos por vagem.

O comprimento da vagem por planta e o número de grãos por vagem são características de produção normalmente resistentes às modificações induzidas por estresse ambiental
(FERREIRA et al., 1991) corroborado por Andrade et al. (1998), que comentam que o número de sementes por vagem é uma característica de alta herdabilidade genética, sendo pouco influenciada pelo ambiente.

Na variável produtividade de grão (PG), foi possível ajustar um modelo linear para lâmina e quadrático para doses de P (FIG. 5). A maior PG ocorreu com a lâmina de $257,2 \mathrm{~mm}\left(1.420,51 \mathrm{~kg} \mathrm{ha}^{-1}\right)$. Esse resultado é superior a média nacional que é de $760 \mathrm{~kg} \mathrm{ha}^{-1}$, conforme IBGE (2005), mas similar a produtividade média de grãos encontrada por Vilarinho et al. (2006), onde verificaram média de $1.243 \mathrm{~kg} \mathrm{ha}^{-1}$ para o feijão-caupi BRS Novaera, para o cultivo em Roraima. Ao contrário, Miranda et al. (2000), trabalhando com dois níveis de irrigação (426 e $338 \mathrm{~mm})$ e três doses de fósforo $\left(250 ; 500\right.$ e $1000 \mathrm{~kg} \mathrm{ha}^{-1}$ de $\left.\mathrm{P}_{2} \mathrm{O}_{5}\right)$, obtiveram resposta de interação entre os tratamentos com feijão comum.

Com a função de PG para as doses de fósforo na cultura do feijão-caupi, foi possível ajustar a melhor dose (120 kg de $\mathrm{P}_{2} \mathrm{O}_{5}$ ), para obtenção da máxima produtividade $\left(1.343,078 \mathrm{~kg} \mathrm{ha}^{-1}\right)$ (FIG. 5). Barrios et al. (1970), verificaram ausência de resposta da adubação fosfatada para o feijão comum em solos com $15 \mathrm{mg} \mathrm{dm}^{-3} \mathrm{de} \mathrm{P}$, comprovando a diminuição da produção com o aumento das doses de P, em solos que apresentam alto teor do nutriente disponível.

A dose de máxima eficiência econômica foi de $89,45 \mathrm{~kg}$ de $\mathrm{P}_{2} \mathrm{O}_{5}$, produzindo $1.306,54 \mathrm{~kg} \mathrm{ha}^{-1}$ de feijãocaupi. Com a redução de $25,46 \%$ na aplicação de fósforo, houve uma perda na PG de apenas 36,54 $\mathrm{kg} \mathrm{ha}^{-1}$. Resultado similar foi encontrado por Cardoso et al. (2006), que observaram aumento na produtividade de grão de feijãocaupi em Latossolo, com a aplicação de doses de $\mathrm{P}(0 ; 45$; 90 e $\left.135 \mathrm{~kg} \mathrm{P}_{2} \mathrm{O}_{5} \mathrm{ha}^{-1}\right)$. 

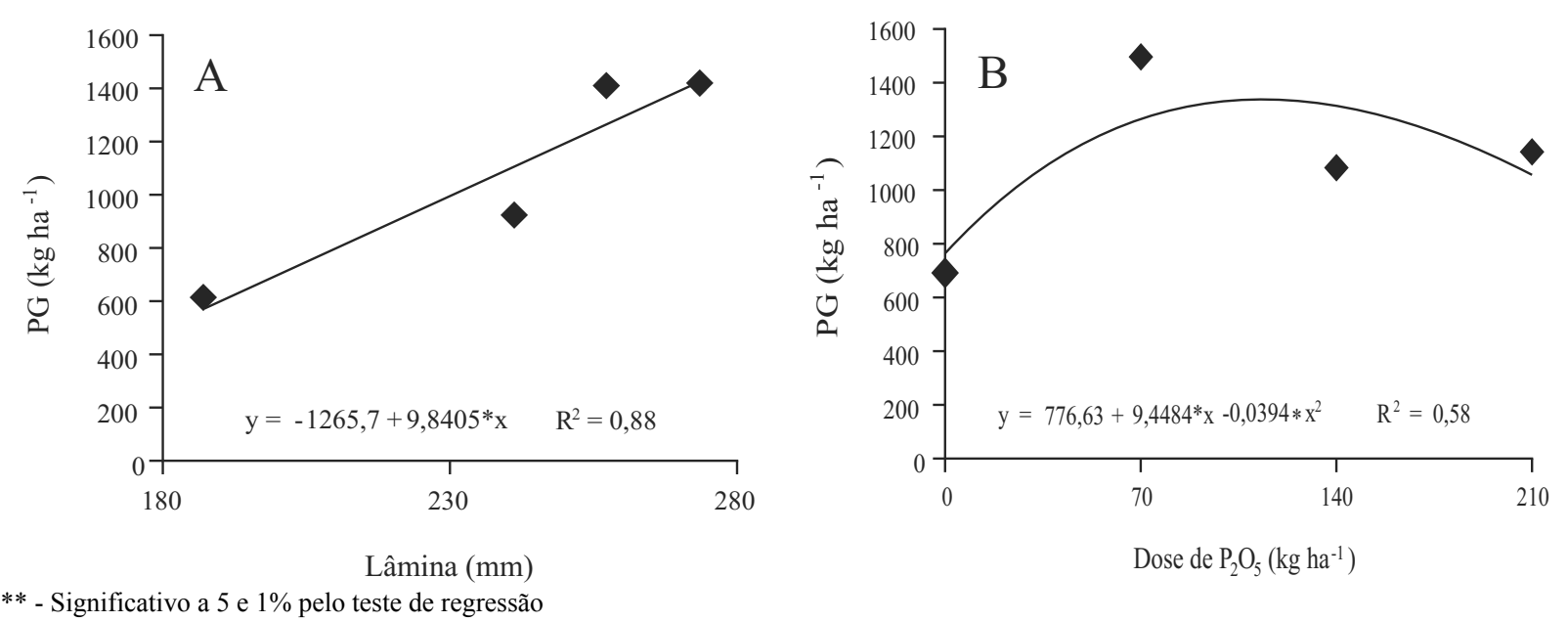

Figura 5 - Produtividade de grãos (PG), em kg ha ${ }^{-1}$, de feijão-caupi em função de lâminas de água (A) e doses de fósforo (B), no cerrado de Roraima, 2009

A menor lâmina de irrigação aplicada (187 mm) reduziu consideravelmente $(43,3 \%)$ a $\mathrm{PG}$, em comparação com a maior lâmina $(273,4$ mm) (FIG. 5). Os componentes da produção, sem exceção, foram menores nos tratamentos sob menor lâmina de água, sendo que este decréscimo foi

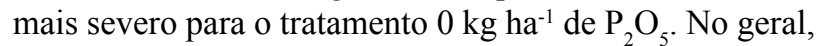
o comprimento da vagem, o número de grãos por vagem e a massa de 100 grãos foram menores no tratamento com aplicação de $187 \mathrm{~mm}$ de água. Este caso pode ser devido ao fato de que, em condições de falta de água na planta, há o aumento da síntese de ácido abscísico e etileno no pedúnculo da flor, provocando sua queda ao menor movimento e impedindo a formação de vagem e grãos. De acordo com Pimentel e Herbert (1999), em condições de deficiência hídrica, a taxa fotossintética das plantas é amplamente comprometida, o que, geralmente, se reflete em reduções na produtividade.

\section{Conclusões}

1. As massas secas da parte aérea e de 100 grãos foram influenciadas significativamente pela interação entre lâminas de água e doses de fósforo;

2. O número de grãos por vagem e o comprimento da vagem foram influenciados somente pelas doses de fósforo;

3. A menor lâmina de irrigação promove redução na produtividade do feijão-caupi, independente da dose de adubação fosfatada;

4. A dose de máxima eficiência econômica é de $89,45 \mathrm{~kg}$ $\mathrm{ha}^{-1}$ de $\mathrm{P}_{2} \mathrm{O}_{5}$, obtendo uma produtividade de grãos de $1.306 \mathrm{~kg} \mathrm{ha}^{-1}$.

\section{Referências}

ANDRADE JÚNIOR, A. S. de et al. Níveis de irrigação na cultura do feijão caupi. Revista Brasileira de Engenharia Agrícola e Ambiental, v. 06, n. 01, p. 17-20, 2002.

ANDRADE, M. J. B. et al. Resposta da cultura do feijoeiro à aplicação foliar de molibdênio e às adubações nitrogenadas de plantio e cobertura. Ciência e Agrotecnologia, v. 22, n. 04, p. 499-508, 1998.

ARAÚJO, W. F. et al. Precipitação pluviométrica mensal provável em Boa Vista, Estado de Roraima, Brasil. Revista Brasileira de Engenharia Agrícola e Ambiental, v. 05, n. 03, p. 563-567, 2001.

BARRIOS, A.; RODRIGUEZ, A. B.; ORTEGA, S. Resultados de ensayos de fertilización em carota (Phaseolus vulgaris L.). Agronomia Tropical, v. 20, n. 05, p. 355-369, 1970.

BEZERRA, F. M. L. et al. Feijão caupi e déficit hídrico em suas fases fenológicas. Revista Ciência Agronômica, v. 34, n. 01, p. 13-18, 2003.

CARDOSO, M. J. et al. Adubação fosfatada e densidades de planta em feijão caupi em solo de tabuleiro costeiro. In: CONGRESSO NACIONAL DE FEIJÃO CAUPI, 2006, Teresina. Anais eletrônicos... Teresina: Embrapa MeioNorte, 2006. Disponível em: <http://www.cpamn.embrapa. br/anaisconac2006>. Acesso em: 13 nov. 2009.

CHRISTIANSEN, J. E. Irrigation by sprinkling. Berkeley: University California, 1942. 124 p. (California Agricultural Experimental Station Bulletin, 670).

COLETA, Q. P. et al. Resposta da cultura do feijoeiro a diferentes doses de adubação fosfatada em latossolo da região da zona da mata de rondônia. In: II SEMINÁRIO DE PESQUISA E EXTENSÃO RURAL - SEPEX “A agricultura 
familiar no agronegócio". Fundacao Universidade Federal de Rondonia - 14 de Junho de 2008.

COSTA, M. M. M. N. et al. Produção, componentes de produção, crescimento e distribuição das raízes de caupi submetido à deficiência hídrica. Pesquisa Agropecuária Brasileira, v. 02, n. 01, p. 43-50, 1997.

DUTRA, L. F. et al. Resposta do feijoeiro ao fósforo em dois níveis de umidade no solo. Revista Brasileira de Agrociência, v. 01, n. 02 , p. $91-96,1995$.

FAGERIA, N. K.; BARBOSA FILHO, M. P.; STONE, L. F. Resposta do feijoeiro a adubação fosfatada. In: POTAFÓS. Simpósio destaca a essencialidade do fósforo na agricultura brasileira. Informações Agronômicas, n.102, p. 1-9, 2003.

FAGERIA, N. K.; BARBOSA-FILHO, M. P.; STONE, L. F. Nutrição de fósforo na produção de feijoeiro. In: YAMADA, T., ABDALLA, S.R.S. (Ed.). Fósforo na agricultura brasileira. Piracicaba: Potafos, 2004. p.435-455.

FERREIRA, L. G. R.; COSTA, J. O.; ALBUQUERQUE, I. M. Estresse hídrico nas fases vegetativa e reprodutiva de duas cultivares de caupi. Pesquisa Agropecuária Brasileira, v. 26, n. 07 , p. 2049-1055, 1991.

FILGUEIRAS, G. C. et al. Aspectos socioeconômicos. In: ZILLI, J. E.; VILARINHO, A. A.; ALVES, J. M. A. A Cultura do Feijão caupi na Amazônia Brasileira. Boa Vista, RR: EMBRAPA RORAIMA, 2009. 356 p.

FONSECA, M. R. Nutrição mineral e produção do feijão caupi em função do fósforo e da saturação por bases, em LATOSSOLO AMARELO. 2008. 70f. Dissertação (Mestrado em Agronomia) - Universidade Rural da Amazônia, Pará.

FREIRE FILHO, F. R.; LIMA, J. A. A.; RIBEIRO, V. Q. (Ed.). Feijão caupi: avanços tecnológicos. Brasília: Embrapa Informação Tecnológica, 2005. p. 191-210.

GRANT, C. A. et al. A importância do fósforo no desenvolvimento inicial da planta. Piracicaba: ESALQ, 2001. (Informações Agronômicas, 95).

HANKS, R. J. et al. Line source sprinkler for continuous variable irrigation crop production studies. Soil Science Society of America Journal, v. 40, p. 426-429, 1976.

HSIAO, T. C. Mensuraments of plant water status. In: STEWART, B. A.; NIELSEN, D. R. Irrigation of agricultural crops. Madison: Marcel Dekker, 1990. p. 244-279.

INSTITUTOBRASILEIRODEGEOGRAFIAEESTATÍSTICA (IBGE). Sistema IBGE de recuperação automática - SIDRA, 2005. Disponível em: <htpp://www.sidra.ibge.gov.br/> Acesso em: 15 maio 2009.

LACERDA, C. F. de et al. Eficiência de utilização de água e nutrientes em plantas de feijão-de-corda irrigadas com água salina em diferentes estádios de desenvolvimento. Engenharia Agrícola, v. 29, n. 02, p. 221-230, 2009.

LEITE, M. de L.; VIRGENS FILHO, J. S. das. Produção de matéria seca em plantas de caupi (Vigna unguiculata (L.) Walp) submetidas a déficits hídricos. Publicatio UEPG Ciências
Exatas e da Terra, Ciências Agrárias e Engenharias, v. 10, n. 01, p. 43-51, 2004.

LEITE, M. de L.; RODRIGUES, J. D.; VIRGENS FILHO, J. S. das. Efeitos do déficit hídrico sobre a cultura do caupi, cv. EMAPA- 821. III. Produção. Revista de Agricultura, v. 75, n. 01, p. 9-20, 2000.

LINHARES, L. C. F. Comportamento de três cultivares de caupi, submetidos à omissão de nutrientes, cultivados em amostras de gleissolo de várzea do rio Pará. 2007. $58 \mathrm{f}$. Dissertação (Mestrado em Agronomia) - Universidade Rural da Amazônia, Pará.

MATTEUCCI, M. B. de A.; CARVALHO, B. C. L de. Efeito do fósforo e da densidade de população sobre os componentes do rendimento do feijão-de-corda (Vigna unguiculata L. Walp). I. Características morfológicas. Anais Escola Agronomia e Veterinária, v. 18 n. 01, p. 73-87, 1988.

MENDES, R. M. de S. et al. Relações fonte-dreno em feijãode-corda submetido à deficiência hídrica. Revista Ciência Agronômica, v. 38, n. 01, p. 95-103, 2007.

MERRIAN, J. L.; KELLER, J. Farm irrigation systems evaluation: A guide for management. Logan: Agricultural and Irrigation Engineering Department, Utah State University, 1978. $271 \mathrm{p}$.

MIRANDA, L. N. et al. Produtividade do feijoeiro em resposta a adubação fosfatada e a regime de irrigação em solo de Cerrado. Pesquisa Agropecuária Brasileira, v. 35, n. 04, p. 703-710, 2000.

NASCIMENTO, J. T.; PEDROSA, M. B.; TAVARES SOBRINHO, J. Efeito da variação de níveis de água disponível no solo sobre o crescimento e produção de feijão caupi, vagens e grãos verdes. Horticultura Brasileira, v. 22, n. 02, p. 174-177, 2004.

OLIVEIRA, F. J. de et al. Caracteres agronômicos aplicados na seleção de cultivares de caupi. Revista Ciência Agronômica, v. 34, n. 01, p. 5-11, 2003.

PIMENTEL. C.; HERBERT, G. Potencial fotossintético e condutância estomática em espécies de feijão caupi sob deficiência hídrica. Revista Brasileira de Fisiologia Vegetal, v. 11, n. 01, p. 7-11, 1999.

QUEIROZ P. FILHO, F. et al. Alterações fisiológicas e de produção do caupi (Vigna unguiculata (L.) Walp) cultivado em solo sódico e irrigado com diferentes lâminas. Ciência Agronômica, v. 17, n. 02, p. 57-64, 1986.

RIBEIRO JÚNIOR, J. I.; MELO, A. L. P. de. Guia prático para utilização do SAEG. Viçosa, MG, 2008. 288 p.

RODRIGUES, J. E. L. F.; ALVES, R. N. B; TEIXEIRA, R. N. G; ROSA, E. S. Adubação NPK, na cultura de feijão caupi em agricultura familiar, no Município de Pontas de Pedras-PA. Belém: Embrapa Amazônia Oriental, 2004. 3 p. (Comunicado Técnico, 95.)

ROSALES-SERNAA, R. J. et al. Biomass distribution, maturity acceleration and yield in drought-stressed common bean cultivars. Field crops research, v. 85, n. 02/03, p. 203-211, 2004. 
SANTOS, J. F. dos. et al. Produção e componentes produtivos de variedades de feijão caupi na microregião cariri paraibano. Engenharia Ambiental, v. 06, n. 01, p. 214-222, 2009.

SILVA, R. J. S.; VAHL, L. C. Resposta do feijoeiro à adubação fosfatada num NEOSSOLO LITÓLICO distrófico da região sul do Rio Grande do Sul. Revista Brasileira de Agrociência, v. 08, n. 02, p. 129-132, 2002.

TÁVORA, F. J. A. F.; LOPES, L. H. de O. Deficiência hídrica no consórcio milho x caupi. Pesquisa Agropecuária Brasileira, v. 25, n. 07, p.1011-1022, 1990.

VALDERRAMA, M. et al. Fontes e doses de nitrogênio e fósforo em feijoeiro no sistema plantio direto. Pesquisa Agropecuária Tropical, v. 39, n. 03, p. 191-196, 2009.

VILARINHO, A. A. et al. Recomendação do Cultivar de Feijão caupi BRS Novaera para Cultivo em Roraima. Boa Vista, 2006. 5 p. (Comunicado Técnico, 15.)

VILARINHO, A. A. et al. Desempenho Produtivo de Linhagens de Feijão caupi em Roraima - safras 2004 e 2005. Roraima: Embrapa, 2005. 21 p.

YAMADA, T; ABDALLA, S. R. S. Simpósio destaca a essencialidade do fósforo na agricultura brasileira. Informações agronômicas, n. 102, p. 1-9, 2003. 